\title{
Estimated age of acquisition norms for 834 Portuguese nouns and their relation with other psycholinguistic variables
}

\author{
J. Frederico Marques, Francisca L. Fonseca, A. Sofia Morais, and Inês A. Pinto \\ University of Lisbon, Lisbon, Portugal
}

\begin{abstract}
The main objective of this study is to report rated age of acquisition (AoA) norms for 834 nouns in Portuguese (European). AoA ratings were collected on a 7 point scale, generally following Gilhooly and Logie (1980) procedure with an 8 extra point for "don't know the word" answers. Results were analyzed considering AoA ratings and their standard deviations and considering the relationship between AoA ratings and other psycholinguistic variables (imageability, familiarity, written word frequency, concreteness, number of syllables and number of words). AoA ratings and their standard deviations were significantly and positively correlated, with early acquired word ratings showing higher agreement. Correlation and multiple regression analyses confirmed the major contribution of imageability and familiarity to AoA ratings obtained in other languages. The full database of AoA ratings and other psycholinguistic variables may be downloaded from www.psychonomic.org/archive or www.fpce.ul.pt/pessoal/ulfpfred/aoa.htm.
\end{abstract}

Since the early seventies, several studies have suggested that the age at which words are acquired (age of acquisition, or AoA) is an important predictor of the speed and accuracy with which those words can subsequently be processed in adulthood, with words acquired early in life being processed faster and more accurately than words acquired later (e.g., Carroll \& White, 1973b).

This effect, referred to in the literature as the "age of acquisition" effect (AoA effect), has been reported in many lexical processing tasks including: oral and written picture naming (e.g., Barry, Morrison, \& Ellis, 1997; Bonin, Fayol, \& Chalard, 2001; Ellis \& Morrison, 1998; Morrison, Chappell, \& Ellis, 1997; Severens, Van Lommel, Ratinckx, \& Hartsuiker, 2005), face naming (e.g., Moore \& Valentine, 1998), word naming (e.g., Gilhooly \& Logie, 1981; Morrison \& Ellis, 1995, 2000), category instance fluency (Catling \& Johnston, 2005; Forbes-McKay, Ellis, Shanks, \& Venneri, 2005; Loftus \& Suppes, 1972), word completion (Gilhooly \& Gilhooly, 1979), visual and auditory lexical decision (e.g., Morrison \& Ellis, 1995, 2000; Turner, Valentine, \& Ellis, 1998), naming from definition (Sartori, Lombardi, \& Matiuzzi, 2005) or perceptual identification (Lyons, Teer, \& Rubenstein, 1978). Moreover, although AoA measures are related to other lexical variables, at least in word naming and lexical decision tasks, AoA effects have been found to be independent of different measures of word frequency, familiarity, imageability and word length (Morrison \& Ellis, 2000).

The measurement of AoA has been operationalized in two different ways: a "subjective" measure, corresponding to adult ratings of the AoA of different words; and an "objective" measure based on the performance of children of different ages in object naming tasks. Several studies have shown that both measures of AoA are strongly correlated in different languages (e.g., Carroll \& White, 1973a; De Moor, Ghyselink, \& Brysbaert, 2000; Gilhooly \& Gilhooly, 1980; Jorm, 1991; Lyons et al., 1978; Morrison et al., 1997; Pérez \& Navalón, 2005; Pind, Jonsdottir, Gissurardottir, \& Jonsson, 2000) providing validation for the rating method. Moreover, Bonin, Barry, Méot, and Chalard (2004) showed that the two measures were still significantly correlated when other lexical variables associated with AoA (including conceptual familiarity, word frequency trajectory, cumulative word frequency, imageability and phonological length) were partialled out.

All this evidence would seem to suggest that AoA is an important lexical dimension on its own that can be measured in (at least) two different ways and that influences performance on a very diverse set of tasks. However, both of these contentions are still a matter of ongoing theoretical and methodological debate. On one hand, several criticisms have been pointed out to the two AoA measures and a new measure, "frequency trajectory", has been proposed to examine age-limited learning effects (Bonin et al., 2004; Zevin \& Seidenberg, 2002). On the other hand, the independence of AoA and of AoA effects have been contested, especially in relation to the influence of cumulative word frequency and frequency trajectory (e.g., Bonin et al., 2004; Lewis, Gerhand, \& H. Ellis, 2001; Zevin \& Seidenberg, 2002, 2004).

J. F. Marques, jfredmarq@fpce.ul.pt 
Considering the first issue, it is true that several criticisms can be raised toward the more frequently used AoA measures. The subjective measure based on adult estimates has been more extensively criticized as more contaminated by word frequency and familiarity (Ellis \& Morrison, 1998; Morrison \& Ellis, 2000; Morrison et al., 1997). But the objective measure based on the performance of children of different ages in object naming tasks has also its particular and maybe more serious downfalls. First of all, although in a smaller proportion than subjective AoA, objective AoA is also related to lexical variables such as word frequency or number of phonemes (e.g., Morrison et al., 1997). Moreover, and contrary to subjective AoA, objective AoA is also dependent on the characteristics of the picture stimuli both in terms of words that can be evaluated in this manner (i.e., only concrete words) and in terms of the influence of picture variables such as name agreement or visual complexity (Morrison et al., 1997) that are related to children's performance. More seriously, as Zevin and Seidenberg $(2002,2004)$ have argued, AoA measures are essentially outcome variables that depend on a number of factors which also influence adult processing. In the case of objective AoA this is aggravated by the fact that it corresponds to a performance measure which is used to predict adult performance on similar tasks leading to a circularity problem (Bonin et al., 2004; Zevin \& Seidenberg, 2002, 2004). This is particularly true for picture naming tasks since the objective measure of AoA is also obtained through picture naming.

Zevin and Seidenberg (2002) and Bonin and collaborators (Bonin, 2005; Bonin et al., 2004) have proposed word frequency trajectory, corresponding to the difference between adult and children word frequency written corpus (extracted from reading materials for the two groups), as a more valid index to test age-limited learning effects than AoA measures. In fact, word frequency trajectory accounts for a significant proportion of the variance in AoA measures and is even less correlated to other variables as it is an objective property of words and, as such, is not influenced by the lexical and picture variables that are correlated to standard AoA measures. However, the fact that frequency trajectory is based on word counts from written texts limits its ability to consider the learning of words before the acquisition of reading. Moreover, Bonin et al. (2004) found objective AoA effects over and above word frequency trajectory that may reflect this early learning contribution.

In regards the second issue, although failure to consider cumulative word frequency (i.e., how often words have been encountered throughout life) may account for some of the effects attributed to AoA as demonstrated by Zevin and Seidenberg $(2002,2004)$, both Bonin et al. (2004), Morrison, Hirsch, Chappell, and Ellis (2002) and Stadhagen-Gonzalez, Bowers, and Damian (2004) have showed that AoA still influences performance on several lexical tasks after cumulative word frequency is adequately controlled for.

All in all, we do not consider that these more recent contributions undermine AoA as an important lexical di- mension nor do they undermine the interest of subjective and objective AoA measures as important indexes to this dimension. This claim can be held even if AoA measures are taken as outcome variables that depend on a number of factors which also influence adult processing (Zevin \& Seidenberg, 2002, 2004). In this context, if models of age-limited learning effects are to have an universal application it is important that comparative AoA data may be obtained from a wide range of languages.

The present paper has three main objectives. First is to present AoA ratings for 834 nouns in Portuguese (European) that might serve to aid future research on age-limited learning effects with this language. (For this language only AoA ratings of the Snodgrass \& Vanderwart, 1980, corpus were available in Ventura, 2003; ratings asked with picture presentation.) Second is to present a correlational analysis (including a regression analysis of rated AoA as the dependent variable) of the ratings obtained with a number of other psycholinguistic variables similarly to what has already been done for other languages (e.g., Barca, Burani, \& Arduino, 2002; Bird, Franklin, \& Howard, 2001; Bonin, Peereman, Malardier, Méot, \& Chalard, 2003; Morrison et al., 1997). Finally, a third objective is to present a database of all the dimensions analyzed for future use in research.

\section{METHOD}

\section{Participants}

A total of 110 psychology undergraduate students from the University of Lisbon participated for partial fulfillment of an introductory course requirement. The participants (14 males and 96 females; mean age 18.5 years; range 17-26 years) were all native Portuguese speakers.

\section{Materials and Procedure}

The 834 nouns were selected from word samples from previous studies (Marques, 1997, 2004) and included both concrete and abstract nouns. To avoid participants' fatigue the total sample was randomly divided and ordered in five nouns groups (one with 166 words and four with 167 words) and participants were randomly assigned to one of each groups. Each item was rated by a mean of 22 participants (range 21-23). For the AoA ratings participants were tested in group and asked to estimate on a 7-point scale the age at which they thought they had learned each word of the set (following Gilhooly \& Logie's 1980 procedure). Following Bird et al. (2001) procedure to reduce errors participants circled actually age bands $(0-2,3-4,5-6,7-8,9-10,11-12$, and 13 or more years). An extra eight end point was added for the possibility that participants did not know the word, which was finally considered as meaning learned in adulthood. The age-bands, including this 8 th point were converted to an 8-point scale in the analysis: from 1 (learned at the age of 0-2 years) to 7 (learned at the age of 13 or older), and 8 (learned in adulthood).

\section{RESULTS AND DISCUSSION}

Mean AoA ratings and their respective standard deviations are presented in the full database by alphabetical order in Portuguese along with their English translation. The full database of AoA ratings and other psycholinguistic variables may be downloaded from 
Table 1

Reliability Coefficient (Cronbach's Alpha) of AoA for the Five Sets of Nouns

\begin{tabular}{lrrrrr}
\hline & Set 1 & Set 2 & Set 3 & Set 4 & Set 5 \\
\hline Number of nouns & 166 & 167 & 167 & 167 & 167 \\
Number of raters & 23 & 21 & 21 & 23 & 22 \\
Cronbach's alpha & .99 & .99 & .98 & .99 & .95 \\
\hline
\end{tabular}

Table 2

Interlingual Correlations of Rated AoA Measures

\begin{tabular}{lllc}
\hline & \multicolumn{1}{c}{ Study } & \multicolumn{2}{c}{$\begin{array}{c}\text { Correlation With } \\
\text { Present Study }\end{array}$} \\
\cline { 3 - 4 } Language & \multicolumn{1}{c}{$r^{* *}$} & $n$ \\
\hline English & Bird et al., 2001 & .80 & 165 \\
French & Alario \& Ferrand, 1999 & .82 & 248 \\
Icelandic & Pind et al., 2000 & .69 & 190 \\
Italian & Barca et al., 2002 & .74 & 191 \\
Spanish & Cuetos et al., 1999 & .78 & 117 \\
\hline
\end{tabular}

** Correlation is significant at the .01 level (two-tailed).

www.psychonomic.org/archive or www.fpce.ul.pt/ pessoal/ulfpfred/aoa.htm (where possible updates to the database will be posted). For the total sample, mean AoA was 3.48 with a range between 1.05 and 7.71 and a standard deviation of 1.37. Mean standard deviation of ratings was 1.10 and the correlation between AoA ratings and their respective standard deviations was $.69(p<$ .01 ), suggesting that judges agreed more on their ratings of early acquired words than later acquired words. This is an interesting result that should be further evaluated as it is possible that this higher agreement on early acquired words reflects a larger similarity of early learning that can underlie AoA effects. Considering previously published rated AoA norms for nouns that provide the standard deviation of ratings it is possible to extend this analysis. For Icelandic (Pind et al., 2000), the correlation between AoA ratings and their respective standard deviations is even higher than in the present case, $r=.81(p<.01$, $n=260$ ). In contrast, for Italian (Barca et al., 2002) and French (Alario \& Ferrand, 1999), correlation between AoA ratings and their respective standard deviations is smaller, $r=.41$ for Italian $(p<.01, n=626)$ and $r=$ .47 for French $(p<.01, n=398)$, which suggests that the effect found may be language dependent.

The reliability of the present AoA norms was evaluated in two different manners. First, for each five nouns groups evaluated (corresponding to different subject samples), we calculated Cronbach's alpha as a measure of interitem consistency. Second, we considered the correlation of the common words of our AoA norms to other previously published norms in other languages. These results are presented in Tables 1 and 2.

Regarding interitem consistency, the reliability of the present AoA ratings is very high and in line with was found in other studies for rated AoA (for a recent summary of these data, see Pérez \& Navalón, 2005). Regarding the correlation of the present AoA ratings to other languages, correlations are also high and in line with the interlingual correlations reported in previous studies (for a review see also Pérez \& Navalón, 2005). Both these results suggests that subjects rely on the same kind of information when they rate AoA.

To evaluate the relation of the AoA ratings collected with other psycholinguistic variables, the following measures were considered: number of letters; number of syllables; familiarity ratings (available for 809 nouns) taken from Marques (2004), where participants were asked to rate on a 5-point scale how familiar was the meaning of the word (from $1=$ highly familiar to $5=$ very unfamiliar); written word frequency (available for 790 nouns) taken from a European Portuguese corpus, the "multifunctional computational lexicon of contemporary Portuguese" (Nascimento, Casteleiro, Marques, Barreto, \& Amaro, n.d.) and its correspondent $\log$ transform (computed for the correlational analyses); imageability and concreteness ratings (available for 249 nouns) taken from Marques (2005) where participants were asked to rate these dimensions on 7point scale (from $1=$ less to $7=$ more) following Paivio, Yuille and Madigan (1968) procedure. Table 3 presents means, standard deviations and amplitude for the different variables. Table 4 presents the correlations of the different variables with AoA. Item values of the different measures are presented in the full database. (The full database may be downloaded from www.psychonomic.org/archive or www.fpce.ul.pt/pessoal/ulfpfred/aoa.htm.)

Table 3

Number of Words $(N)$, Means $(M)$, Standard Deviations (SD) and Amplitude $(A)$ for the Variables Age-of-Acquisition (AoA), Familiarity, Written Word Frequency (Freq), Log Written Word Frequency (logFreq), Imageability, Concreteness, Number of Syllables, and Number of Letters

\begin{tabular}{lcrrc}
\hline \multicolumn{1}{c}{ Variable } & $N$ & \multicolumn{1}{c}{$M$} & \multicolumn{1}{c}{$S D$} & \multicolumn{1}{c}{$A$} \\
\hline AoA & 834 & 3.48 & 1.37 & $1.05-7.71$ \\
Familiarity & 808 & 2.29 & .80 & $1.11-4.89$ \\
Freq & 790 & 603.35 & $1,559.90$ & $1-21,896$ \\
logFreq & 790 & 2.14 & .75 & $0-4.34$ \\
Imageability & 249 & 4.87 & 1.67 & $1.60-6.87$ \\
Concreteness & 249 & 4.95 & 1.90 & $1.64-6.86$ \\
Number of Syllables & 834 & 2.84 & .87 & $1-6$ \\
Number of Letters & 834 & 6.63 & 1.96 & $2-13$ \\
\hline
\end{tabular}

Table 4

Correlations of Age-of-Acquisition (AoA) With the Variables Familiarity, Written Word Frequency (Freq), Log Written Word Frequency (logFreq), Imageability, Concreteness, Number of Syllables, and Number of Letters

\begin{tabular}{lcc}
\hline \multirow{2}{*}{ Variable } & \multicolumn{2}{c}{ Correlation With AoA } \\
\cline { 2 - 3 } & $r^{* *}$ & $n$ \\
\hline Familiarity & .78 & 808 \\
Freq & -.25 & 790 \\
logFreq & -.51 & 790 \\
Imageability & -.69 & 249 \\
Concreteness & -.52 & 249 \\
Number of Syllables & .25 & 834 \\
Number of Letters & .28 & 834 \\
\hline
\end{tabular}

Note-The score for Familiarity is inversely proportional to familiarity. ${ }^{* *}$ Correlation significant at the .01 level (two-tailed). 
Table 5

Correlation Matrix for the Data Subset With All Measures $(N=\mathbf{2 4 3})$

\begin{tabular}{|c|c|c|c|c|c|c|c|}
\hline & 1 & 2 & 3 & 4 & 5 & 6 & 7 \\
\hline 1. AoA & - & $.78^{* *}$ & $-.39^{* *}$ & $-.70^{* *}$ & $-.53^{* *}$ & $.41^{* *}$ & $.46^{* *}$ \\
\hline 2. Familiarity & & - & $-.14^{*}$ & $-.86^{* *}$ & $-.74^{* *}$ & $.26^{* *}$ & $.33^{* *}$ \\
\hline 3. $\log$ Freq & & & - & -.10 & $-.25^{* *}$ & $-.36^{* *}$ & $-.39^{* *}$ \\
\hline 4. Imageability & & & & - & $.92^{* *}$ & $-.25^{* *}$ & $-.29^{* *}$ \\
\hline 5. Concreteness & & & & & - & $-.19^{* *}$ & $-.23^{* *}$ \\
\hline 6. Syllables & & & & & & - & $.88^{* *}$ \\
\hline 7. Letters & & & & & & & - \\
\hline
\end{tabular}

${ }^{*}$ Correlation significant at the .05 level (two-tailed). ${ }^{* *}$ Correlation significant at the .01 level (two-tailed).

Overall, correlations of AoA with the other dimensions are similar to the ones obtained in previous studies in which these same variables were considered (e.g., Bird et al., 2001, and Morrison et al., 1997, for English; and Barca et al., 2002, for Italian). In all these studies, imageability, familiarity, and written word frequency are the dimensions more consistently related to rated AoA (in the present study, $r=.78$ for familiarity; $r=-.69$ for imageability; and $r=-.51$ for $\log$ written word frequency; all $r$ 's significant at $p<.01$ ). Concreteness also appears to be importantly related to AoA $(r=-.52, p<$ .01 ) in the present study and in Barca et al. (2002) but not in Bird's et al. (2001) study (Morrison et al., 1997, did not consider this dimension). However, this has to do with the fact that this study considers not only nouns but also verbs and function words and concreteness is related to word class (Bird et al., 2001).

To further compare the present results with these studies (except with Barca et al., 2002, that does not provide this analysis) we similarly performed a multiple regression analysis of the data subset for which we had all measures $(N=243)$ using AoA as the dependent variable, and imageability, familiarity, $\log$ transform written word frequency, syllables and letters as independent variables. Table 5 presents the correlation matrix of all variables for this subset and Table 6 presents the results of the multiple regression analysis. Beyond the correlations of the different variables with AoA that are in line with what was found for the total set (see Table 3), a special emphasis

Table 6

Multiple Regression Analysis With AoA As the Dependent Variable and Imageability, Familiarity, Log Written Word Frequency (logFreq), Concreteness, Number of Syllables, and Number of Letters As Independent Variables

\begin{tabular}{lcccc}
\hline & \multicolumn{4}{c}{ Coefficient } \\
\cline { 2 - 5 } \multicolumn{1}{c}{ Variable } & \multicolumn{2}{c}{ Unstandardized } & \multicolumn{2}{c}{ Standardized } \\
\cline { 2 - 5 } \cline { 3 - 5 } Imageability & -.51 & .09 & -.63 & $-5.53^{* *}$ \\
Familiarity & .65 & .14 & .36 & $4.84^{* *}$ \\
logFreq & -.53 & .08 & -.29 & $-6.74^{* *}$ \\
Concreteness & .19 & .07 & .27 & $2.93^{* *}$ \\
Number of Syllables & .10 & .10 & .07 & .98 \\
Number of Letters & .03 & .05 & .04 & .57
\end{tabular}

Note-The score for Familiarity is inversely proportional to familiarity. ${ }^{* *} p<.01$. goes to the strong and significant correlations found between familiarity and imageability $(r=-.86, p<.01)$, syllables and letters $(r=-.88, p<.01)$ and imageability and concreteness $(r=.92, p<.01)$. These correlations are in agreement with previous studies (e.g., Barca et al., 2002; Bird et al., 2001; Morrison et al., 1997; Paivio et al., 1968), but present higher values, especially for the latter case.

Regarding the multiple regression, the overall regression equation was significant $[F(6,236)=5.72, p<.01$, $R=.863$ ], and, taken together, the predictor variables accounted for $74 \%$ of the variance. In terms of significant predictors $(p<.01)$, the results are once again in general agreement with Bird et al. (2001) and Morrison et al. (1997) showing that the main predictors of rated AoA are imageability, followed by familiarity, word frequency and concreteness (all significant for $p<.01$ ), with word extension measures coming up last (and not significant in the present case).

\section{CONCLUSIONS}

In the present study we collected age of acquisition ratings for a total of 834 nouns in Portuguese (European) and evaluated its relationship with a number of other psycholinguistic variables that have shown to be related to rated AoA (e.g., Bird et al., 2001; Morrison et al., 1997), imageability, familiarity, written word frequency, concreteness, and word extension (number of syllables and number of letters). Correlation and multiple regression results replicated studies with other languages especially emphasizing the association of imageability and familiarity to AoA ratings also for Portuguese. Nevertheless, the fact that the magnitude of these relations varies across languages, emphasizes the need of collecting normative data for each language.

With regard to AoA norms an interesting and unexpected result was the strong and positive correlation between AoA ratings and their respective standard deviations that suggests that ratings of early acquired words receive more agreement than later acquired words. This tendency was also found in previous studies (Barca et al., 2002; Bonin et al., 2003; Pind et al., 2000) but with different magnitudes, suggesting that this may be a language-dependent phenomenon. Further research with different languages 
and different AoA measures will be needed to understand more fully the significance of these results.

\section{AUTHOR NOTE}

This research was supported by the Centro de Psicometria e Psicologia da Educação da Universidade de Lisboa. We thank Joana Carmo for her help on data coding and Hannah Mossman for her thorough proofreading. Correspondence should be addressed to J. Frederico Marques, Faculdade de Psicologia e de Ciências da Educação, Universidade de Lisboa, Alameda da Universidade, 1649-013 Lisboa, Portugal (e-mail: jfredmarq@fpce.ul.pt).

\section{REFERENCES}

Alario, F.-X., \& Ferrand, L. (1999). A set of 400 pictures standardized for French: Norms for name agreement, image agreement, familiarity, visual complexity, image variability, and age of acquisition. Behavior Research Methods, Instruments, \& Computers, 31, 531-552.

Barry, C., Morrison, C., \& Ellis, A. (1997). Naming the Snodgrass and Vanderwart pictures: Effects of age of acquisition, frequency, and name agreement. Quarterly Journal of Experimental Psychology, 50A, 560-585.

Barca, P., Burani, C., \& Arduino, L. (2002). Word naming times and psycholinguistic norms for Italian nouns. Behavior Research Methods, Instruments, \& Computers, 34, 424-434.

Bird, H., Franklin, S., \& Howard, D. (2001). Age of acquisition and imageability ratings for a large set of words including verbs and function words. Behavior Research Methods, Instruments, \& Computers, 33, 73-79.

Bonin, P. (2005). Comment accè-t-on à un mot en production verbale écrite? [Lexical access in written word production]. Psychologie Française, 50, 323-338.

Bonin, P., Barry, C., MÉot, A., \& Chalard, M. (2004). The influence of age of acquisition in word reading and other tasks: A never ending story? Journal of Memory \& Language, 50, 456-476.

Bonin, P. Fayol, M., \& Chalard, M. (2001). Age of acquisition and word frequency in written picture naming. Quarterly Journal of Experimental Psychology, 54A, 469-489.

Bonin, P., Peereman, R., Malardier, N., Méot, A., \& Chalard, M. (2003). A new set of 299 pictures for psycholinguistic studies: French norms for name agreement, image agreement, conceptual familiarity, visual complexity, image variability, age of acquisition, and naming latencies. Behavior Research Methods, Instruments, \& Computers, 35, 158-167.

Carroll, J., \& White, M. (1973a). Age of acquisition norms for 220 pictureable nouns. Journal of Verbal Learning \& Verbal Behavior, $122,563-576$

Carroll, J., \& White, M. (1973b). Word frequency and age of acquisition as determiners of picture naming latency. Quarterly Journal of Experimental Psychology, 12, 85-95.

Catling, J. C., \& Johnston, R. A. (2005). Age of acquisition effects on word generation. European Journal of Cognitive Psychology, 17, $161-177$

Coltheart, M. (1981). The MRC Psycholinguistic Database. Quarterly Journal of Experimental Psychology, 33A, 447-505.

De Moor, W., GHYSELInCK, M., \& BrysBaerT, M. (2000). A validation study of the age-of-acquisition norms collected by Ghyselinck, De Moor, \& Brysbaert. Psychologica Belgica, 40, 99-114.

Ellis, A., \& Morrison, C. (1998). Real age-of-acquisition effects in lexical retrieval. Journal of Experimental Psychology: Learning, Memory, \& Cognition, 24, 515-523.

Forbes-McKay, K. E., Ellis, A. W., Shanks, M. F., \& Venneri, A. (2005). The age of acquisition of words produced in a semantic fluency task can reliably differentiate normal from pathological age. Neuropsychologia, 43, 1625-1632.

Gilhooly, K., \& Gilhooly, M. (1979). Age-of-acquisition effects in lexical and episodic memory tasks. Memory \& Cognition, 7, 214-223.

Gilhooly, K., \& Gilhooly, M. (1980). The validity of age-of-acquisition ratings. British Journal of Psychology, 71, 105-110 .

Gilhooly, K., \& Logie, R. (1980). Age-of-acquisition, imagery, con- creteness, familiarity, and ambiguity measures for 1,944 words. Behavior Research Methods \& Instrumentation, 12, 395-427.

GiLhooly, K., \& Logie, R. (1981). Word age-of-acquisition, reading latencies, and auditory recognition. Current Psychological Research, 1, 251-262.

JoRM, A. F. (1991). The validity of word age-of-acquisition ratings: A longitudinal study of a child's word knowledge. British Journal of Developmental Psychology, 9, 437-444.

Lewis, M., Gerhand, S., \& Ellis, H. (2001). Reevaluating age-ofacquisition effects: Are they simply cumulative-frequency effects? Cognition, 78, 189-205.

LOFTUs, E., \& SuPPES, P. (1972). Structural variables that determine the speed of retrieving words from long term memory. Journal of Verbal Learning \& Verbal Behavior, 11, 770-777.

Lyons, A., Teer, P., \& Rubenstein, H. (1978). Age-of-acquisition and word recognition. Journal of Psycholinguistic Research, 7, 179-187.

MARQues, J. F. (1997). Normas de tipicidade e familiaridade para diferentes categorias de itens verbais [Typicality and familiarity measures for different categories of verbal items]. Revista Portuguesa de Psicologia, 32, 35-55.

Marques, J. F. (2004). Normas de familiaridade para substantivos comuns [Familiarity norms for common nouns]. Laboratório de Psicologia, 2, 5-19.

MARQUES, J. F. (2005). Normas de imagética e concreteza para substantivos comuns [Imageability and concreteness norms for common nouns]. Laboratório de Psicologia, 3, 65-75.

Moore, V., \& Valentine, T. (1998). The effect of age of acquisition on speed and accuracy of naming famous faces. Quarterly Journal of Experimental Psychology, 51A, 485-513.

Morrison, C., Chappell, T., \& Ellis, A. (1997). Age of acquisition norms for a large set of object names and their relation to adult estimates and other variables. Quarterly Journal of Experimental Psychology, 50A, 528-559.

Morrison, C., \& Ellis, A. (1995). The role of word frequency and age of acquisition in word naming and lexical decision. Journal of Experimental Psychology: Learning, Memory, \& Cognition, 21, 116-133.

Morrison, C., \& Ellis, A. (2000). Real age of acquisition effects in word naming and lexical decision. British Journal of Psychology, 91, 167-180.

Morrison, C., Hirsh, K., Chappell, T., \& Ellis, A. (2002). Age and age of acquisition: An evaluation of the cumulative frequency hypothesis. European Journal of Cognitive Psychology, 14, 435-459.

Nascimento, M. F. B., Casteleiro, J. M., Marques, M. L. G., BarRETo, F., \& Amaro, R. (no date). Léxico multifuncional computorizado do português contemporâneo [Multifunctional computational lexicon of contemporary Portuguese] (data file). Available from Centro de Linguística da Universidade de Lisboa Web site: www.clul.ul.pt.

Paivio, A., Yuille, J. C., \& Madigan, S. A. (1968). Concreteness, imagery, and meaningfulness values for 925 nouns. Journal of Experimental Psychology, 76, (1, Pt.2).

Pérez, M. A., \& Navalón, C. (2005). Objective AoA norms for 175 names in Spanish: Relationships with other psycholinguistic variables, estimated AoA, and data from other languages. European Journal of Cognitive Psychology, 17, 179-206.

Pind, J., Jonsdottir, H., Gissurardottir, H., \& Jonsson, F. (2000). Icelandic norms for the Snodgrass and Vanderwart (1980) pictures: Name and image agreement, familiarity, and age of acquisition. Scandinavian Journal of Psychology, 41, 41-88.

Sartori, G., Lombardi, L., \& Mattiuzzi, L. (2005). Semantic relevance best predicts normal and abnormal name retrieval. Neuropsychologia, 43, 754-770.

Severens, E., Van Lommel, S., Ratinckx, E., \& Hartsuiker, R. J. (2005). Timed picture naming norms for 590 pictures in Dutch. Acta Psychologica, 119, 159-187.

SNODGRASS, J. G., \& VANDERWART, M. (1980). A standardized set of 260 pictures: Norms for name agreement, image agreement, familiarity, and visual complexity. Journal of Experimental Psychology: Human Learning \& Memory, 6, 174-215.

Stadthagen-Gonzalez, H., Bowers, J., \& Damian, M. (2004). Ageof-acquisition effects in visual word recognition: Evidence from expert vocabularies. Cognition, 93, B11-B26.

Turner, J., Valentine, T., \& Ellis, A. (1998). Contrasting effects of 
age of acquisition and word frequency on auditory and visual lexical decision. Memory \& Cognition, 26, 1282-1291.

Ventura, P. (2003). Normas para as figuras de Snodgrass e Vanderwart (1980) [Norms for the Snodgrass and Vanderwart (1980) figures]. Laboratório de Psicologia, 1, 5-19.

Zevin, J. D., \& Seidenberg, M. (2002). Age-of-acquisition effects in word reading and other tasks. Journal of Memory \& Language, 47, 1-29.

Zevin, J. D., \& SeIDenberg, M. (2004). Age-of-acquisition effects in reading aloud: Tests of cumulative frequency and frequency trajectory. Memory \& Cognition, 32, 31-38.

\section{ARCHIVED MATERIALS}

The following materials associated with this article may be accessed through the Psychonomic Society's Norms, Stimuli, and Data archive, www.psychonomic.org/archive.
To access these files, search the archive for this article using the journal name (Behavior Research Methods), the first author's name (Marques), and the publication year (2007).

FILE: MarquesEtAlBRM.xls.

DESCRIPTION: This file contains AoA norms and other psycho linguistic variables as described in Marques et al. (2007).

FILE: MarquesEtAlBRMnorms.txt.

DESCRIPTION: This file contains the above information in text format FILE: MarquesEtAlBRMvariables.txt.

DESCRIPTION: This file contains the description of the variables used in the above files in .txt format.

Note that these files and possible future extensions (e.g., the full database of AoA ratings, other psycholinguistic variables, etc.) are also available on the author's Web site: www.fpce.ul.pt/pessoal/ulfpfred/aoa.htm.

(Manuscript received December 29, 2005; revision accepted for publication April 26, 2006.) 